\title{
Genetically-determined variations in photosynthesis indicate roles for specific fatty acid species in chilling responses
}

\author{
Donghee Hoh ${ }^{1}$, Patrick Horn ${ }^{2}$, Atsuko Kanazawa ${ }^{1}$, John E. Froehlich ${ }^{1}$, Jeffrey Cruz ${ }^{3}$, \\ Oliver Tessmer ${ }^{1}$, David Hall ${ }^{1}$, Lina Yin ${ }^{4}$, Christoph Benning ${ }^{1}$, and David M. Kramer ${ }^{3}$ \\ ${ }^{1}$ Michigan State University \\ ${ }^{2}$ East Carolina University \\ ${ }^{3}$ MSU-DOE Plant Research Laboratory \\ ${ }^{4}$ Northwest A\&F University
}

October 31, 2021

\begin{abstract}
Using a population of recombinant inbred lines (RILs) cowpea (Vigna unguiculata. L. Walp), we tested for co-linkages between lipid contents and chilling responses of photosynthesis. Under low temperature conditions $\left(19^{\circ} \mathrm{C} / 13^{\circ} \mathrm{C}\right.$, day $/$ night $)$, we observed co-linkages between quantitative trait loci (QTL) intervals for photosynthetic light reactions and specific fatty acids, most

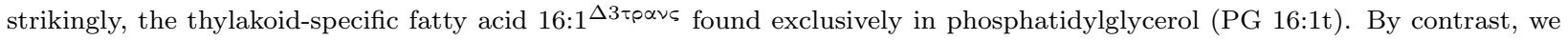
did not observe co-associations with bulk polyunsaturated fatty acids or high-melting-point-PG (sum of PG 16:0, PG 18:0 PG 16:1t) previously thought to be involved in chilling sensitivity. These results suggest that in cowpea, chilling sensitivity is modulated by specific lipid interactions rather than bulk properties. We were able to recapitulate the predicted impact of PG 16:1t levels on photosynthetic responses at low temperature using mutants and transgenic Arabidopsis lines. Because PG 16:1t synthesis requires the activity of peroxiredoxin-Q, which is activated by $\mathrm{H}_{2} \mathrm{O}_{2}$ and known to be involved in redox signaling, we hypothesize that the accumulation of PG 16:1t occurs as a result of upstream effects on photosynthesis that alter redox status and production of reactive oxygen species.
\end{abstract}

\section{Hosted file}

Hoh et al 2021-Lipid.pdf available at https://authorea.com/users/441110/articles/543750genetically-determined-variations-in-photosynthesis-indicate-roles-for-specific-fattyacid-species-in-chilling-responses 